\title{
Physical stability of different chitosan salts in matrix tablet formulations
}

\author{
Kampanart Huanbutta ${ }^{1,2}$, \\ Tanikan Sangnim ${ }^{1,2}$, \\ Kamonrak Cheewatanakornkool ${ }^{2,4}$, \\ Lalinthip Sutthapitaksakul ${ }^{2,3}$, \\ Kasitpong Thanawuth ${ }^{2,3}$, \\ Pornsak Sriamornsak ${ }^{2,3,5 *}$ \\ ${ }^{1}$ Faculty of Pharmaceutical Sciences, Burapha \\ University, Chonburi, Thailand \\ ${ }^{2}$ Pharmaceutical Biopolymer Group (PBiG), \\ Faculty of Pharmacy, Silpakorn University, \\ Nakhon Pathom, Thailand \\ ${ }^{3}$ Department of Pharmaceutical Technology, \\ Faculty of Pharmacy, Silpakorn University, \\ Nakhon Pathom, Thailand \\ ${ }^{4}$ Pharma Nueva Co., Ltd., Chatuchak, Bangkok, \\ Thailand \\ ${ }^{5}$ Academy of Science, Royal Society of Thailand, \\ Bangkok, Thailand
}

*Corresponding author:

Pornsak Sriamornsak

sriamornsak_p@su.ac.th

\begin{abstract}
This study aimed to evaluate the physical stability of chitosan (CS) and its salt forms, including chitosan glycolate (CGY) and chitosan lactate (CL), as diluent in matrix tablets for the modified-release dosage form. Caffeine, theophylline, and theobromine were selected as model drugs in this study because of its similarity in chemical structure but difference in solubility. In vitro drug release, hardness, and tablet weight of the drug-loaded matrix tablets made of CS or CS salts were assessed after preparation and 6 months of storage for physical stability monitoring. After 6 months under the accelerated storage condition, the hardness of the CS and CS salt matrix tablets without drug increased, whereas the hardness of the drug-loaded matrix tablets decreased. After 6 months, the weight gain of the CS matrix tablets was approximately $2.63 \%$ to $4.97 \%$. In addition, storage of the CGY and CL matrix tablets for 6 months significantly caused rapid drug release. Results show that the application of CS as tablet excipient should be closely monitored and evaluated because of its low stability and hygroscopic property.
\end{abstract}

\section{INTRODUCTION}

Chitosan (CS) is a positively charged polysaccharide comprising copolymers of glucosamine $(\beta(1-4)$-linked 2 -amino2-deoxy-D-glucose) and $N$-acetylglucosamine (2-acetamido2-deoxy-D-glucose). CS is obtained after the deacetylation of chitin obtained from the exoskeletons of crustaceans after demineralization and deproteinization treatments ${ }^{1}$. Recently, there has been growing interest in the use of CS as drug release controller and other pharmaceutical excipients in various pharmaceutical dosage forms, for instance, matrix tablets, compression-coated tablets, film-coated tablets, and nano/ microparticles ${ }^{1-5}$. Nevertheless, native CS in base form has been rarely used because of its low water solubility. Consequently, CS was modified into several salt forms to improve its solubility ${ }^{6-8}$. In pharmaceutical tablet formulation, $\mathrm{CS}$ and its salts have been widely utilized as binder in the wet/dry granulation process, lubricant, tablet diluent, film coating material, and controlled drug release agent ${ }^{9-12}$. Apart from its application as pharmaceutical excipient, established human exposure to $\mathrm{CS}$ has occurred through https://www.pharmacy.mahidol.ac.th/journal/ (Thailand) 2020 
its use as a dietary supplement in preparations for obesity and hypercholesterolemia ${ }^{13,14}$. Even though $\mathrm{CS}$ and its salts have been applied as pharmaceutical excipient for a long time, information about the physical stability of CS is still lacking. Thus, the information about the physical stability of CS and its salts would help formulators aware and concern about using CS in various pharmaceutical dosage forms.

This study aimed to evaluate the physical stability of CS and its salts, including chitosan glycolate (CGY) and chitosan lactate (CL) (Figure 1), in matrix tablet dosage forms. In vitro drug release profiles, hardness, and tablet weight of drug-loaded matrix tablets made of CS or CS salts were assessed after preparation and 6 months of storage. Two molecular weights (MW) of CS, i.e., 45 and 200 $\mathrm{kDa}$, with the degree of deacetylation of $87 \%$ to $89 \%$ were used. Three structurally similar drugs, namely, caffeine, theophylline, and theobromine (Figure 2) were selected as model drugs in this study because of their difference in solubility.
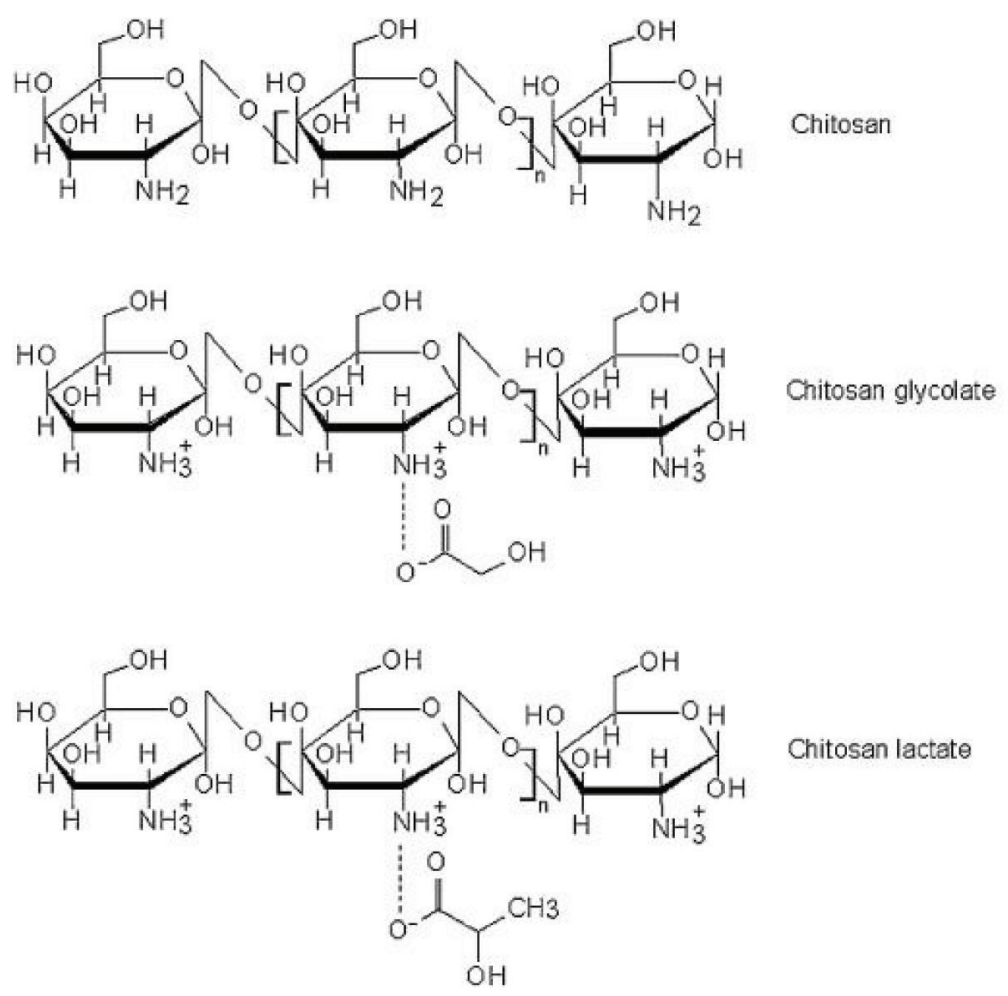

Figure 1. Chemical structures of chitosan (CS), chitosan glycolate (CGY), and chitosan lactate (CL)<smiles>Cn1c(=O)c2c(ncn2C)n(C)c1=O</smiles>

Caffeine

(1,3,7-trimethylxanthine)<smiles>Cn1c(=O)c2[nH]cnc2n(C)c1=O</smiles>

Theophylline

(1,3-dimethylxanthine)<smiles>Cn1cnc2c1c(=O)[nH]c(=O)n2C</smiles>

Theobromine

(3,7-dimethylxanthine)

Figure 2. Illustration of the chemical structures of caffeine, theophylline, and theobromine 


\section{MATERIALS AND METHODS}

\subsection{Materials}

CS with the degree of deacetylation of $87 \%$ to $89 \%$ and $\mathrm{MW}$ of $45 \mathrm{kDa}$ (CS45) and $200 \mathrm{kDa}(\mathrm{CS} 200)$ was purchased from Seafresh Co. Ltd., Thailand (lot numbers COA050507 and COA240702, respectively). Caffeine was obtained from BASF (Thai) Co.Ltd., Thailand. Theophylline and theobromine were purchased from Sigma Aldrich, USA. All excipients were of pharmaceutical grade, and other chemicals were of reagent grade.

\subsection{Preparation of CGY and CL}

CGY and CL were prepared by the spray drying technique, as described in a previous report ${ }^{15}$. Briefly, CS flakes were dissolved in either glycolic acid or lactic acid solution. Then, the CS solutions were spray-dried using a spray dryer (model SD60, Labplant, UK) under the following conditions: inlet temperature of $140{ }^{\circ} \mathrm{C}$, outlet temperature of $80{ }^{\circ} \mathrm{C}$ to $90^{\circ} \mathrm{C}$, and feeding rate of $5 \mathrm{~mL} / \mathrm{min}$. The obtained powders were collected and kept in a desiccator. Successful CS salt modification was confirmed by Fourier transform infrared spectroscopy, as reported in a previous study ${ }^{16}$.

\subsection{Preparation of drug-loaded matrix tablets made of CS or CS salts}

Two hundred milligrams of CS or CS salts mixed with $100 \mathrm{mg}$ of the model drug (caffeine, theophylline, or theobromine) were compressed into tablets using a hydraulic press (Specac Inc., UK) at a fixed compression force of 2 tons and dwelling time of $20 \mathrm{~s}$ using a $9.5-\mathrm{mm}$ diameter flat-faced punch set. The compressed tablets were kept in a desiccator at ambient temperature before further investigation. The compressed tablets were also kept in a stability chamber under the accelerated storage condition $\left(45^{\circ} \mathrm{C}, 75 \%\right.$ relative humidity) for 6 months for physical stability monitoring.

\subsection{Physical properties of drug-loaded matrix tablets made of CS or CS salts}

The thickness and diameter of the matrix tablets were measured using a caliper (Dial Thickness Gauge, Mitutoyo, Japan). The tablet hardness was measured on the first day and after 6-month storage using a texture analyzer (model TA-XT plus, Stable Micro System, UK) in compression mode. The images of the tablets containing CS and CS salts were recorded on the first day and after 6-month storage.

\subsection{Weight change}

The change in tablet weight was monitored to observe the hygroscopicity of CS and CS salts as the excipient in matrix tablets. After the preparation of the tablets, the initial weight $\left(\mathrm{W}_{1}\right)$ was recorded using an analytical balance (model AG204, Mettler-Toledo, Switzerland). Then, the prepared tablets were kept in a stability chamber for 6 months and weighed again $\left(\mathrm{W}_{2}\right)$. The percentage of weight increase due to absorbed ambient humidity was estimated using Eq. (1):

$$
\text { Weight change }=\left[\frac{\left(\mathrm{W}_{2}-\mathrm{W}_{1}\right)}{\mathrm{W}_{1}}\right] \times 100
$$

\subsection{In vitro release studies}

The drug release behavior of the drug-loaded matrix tablets containing CS or its salts was investigated using the USP dissolution apparatus I (model Dissolutest, Prolabo, France) equipped with baskets, which was operated at a speed of $100 \mathrm{rpm}$ and equilibrated to $37 \pm 0.5^{\circ} \mathrm{C}$. The release studies were initially performed in $\mathrm{pH} 1.2$ simulated gastric fluid (without pepsin) of the USP for $2 \mathrm{~h}$, which was then replaced with $\mathrm{pH} 6.8$ Tris buffer to simulate the intestinal conditions for the following hours. The samples $(5 \mathrm{~mL})$ were taken at various time intervals, i.e., $5 \mathrm{~min}, 10 \mathrm{~min}, 15 \mathrm{~min}, 30 \mathrm{~min}$, $1 \mathrm{~h}, 2 \mathrm{~h}, 4 \mathrm{~h}, 6 \mathrm{~h}, 8 \mathrm{~h}, 12 \mathrm{~h}$, and $24 \mathrm{~h}$. Then, the amount of drug released was measured by a UVvisible spectrophotometer (model Lambda 2, Perkin Elmer, Germany) at maximum wavelengths of 272, 270, and $272 \mathrm{~nm}$ for caffeine, theophylline, and theobromine, respectively. Each in vitro release study was performed in triplicate.

\subsection{Statistical analysis}

Analysis of variance and Levene's test for homogeneity of variance were performed using SPSS version 10.1 for Windows (SPSS Inc., USA). Post hoc testing $(\mathrm{p}<0.05)$ of the multiple comparisons 
was performed using either the Scheffé or GamesHowell test depending on whether Levene's test was insignificant or significant, respectively ${ }^{17}$.

\section{RESULTS AND DISCUSSION}

\subsection{Physical properties and appearance of drug- loaded matrix tablets containing CS or its salts}

The hardness properties of the matrix tablets containing CS or its salts are shown in Figure $3 \mathrm{a}$. The hardness of all tablets was between $3.5 \mathrm{~kg}$ and $18.7 \mathrm{~kg}$. For CS with the same MW, CGY matrix tablets exhibited higher hardness than CS and CL matrix tablets. This finding can be attributed to the chemical structure of CGY that contains the hydroxyl group, which might interact with the amine group of other CS units and then yield hydrogen bonds. By contrast, $\mathrm{CL}$ contains the $\mathrm{CH}_{3}$ group, which might cause steric hindrance that interferes with the interaction between polymer chains (Figure 1). This result is consistent with that of our previous study, in which the CGY matrix tablets exhibited higher tablet hardness and tablet strength than the CS, $\mathrm{CL}$, chitosan aspartate, and chitosan glutamate matrix tablets ${ }^{18}$. Furthermore, the addition of model drugs (caffeine, theophylline, or theobromine) in the tablets containing CS or CS salts distinctly increased tablet hardness. This is likely due to the compressibility and compactibility of the active drugs, as also mentioned in other reports ${ }^{19,20}$. Moreover, in the case of CS and CGY, the tablets made of low MW (45 kDa) with no drug exhibited higher hardness than those made of high MW (200 kDa). The results of this study are consistent with those of previous studies ${ }^{18,21}$, which show that CS with high MW has high viscosity, resulting in large particles of the spray-dried product that lead to low hardness of the resultant tablets.

After 6 months of storage in the stability chamber, the blank matrix tablets containing CS salts were six times harder (from $100 \%$ to $600 \%$ ), as presented in Figure $3 \mathrm{~b}$ and 4 . This finding can be attributed to the fact that CS is hygroscopic in nature, which means that it has a high capability to form the hydrogen bond (formed with both the hydroxyl and amino groups) with water. This phenomenon was previously reported in other studies $^{22,23}$, which explained that a moisture content of $6 \%(\mathrm{w} / \mathrm{w})$ or higher improves the particle binding property, resulting in tablets with high hardness. Therefore, the hardness of the blank matrix tablets was dramatically increased. By contrast, polymer-polymer interaction was hindered by the drug molecules in the drug-loaded matrix tablets, resulting in a stable tablet hardness during 6 months of storage. Finally, the weight of the tablets containing CS salts is more stable than that of the tablets containing CS. This finding can be attributed to the modification of active moieties in the chemical structure of CS, which can prevent the interaction of polymer with water molecules in the air ${ }^{24}$.

\subsection{Weight change}

The percentage of weight change after 6 months of storage of the matrix tablets containing CS and CS salts was monitored to evaluate the hygroscopic property of CS and its salts as the excipient in solid dosage forms. The initial weight of all matrix tablets ranged from $203.13 \mathrm{mg}$ to $224.75 \mathrm{mg}$. As illustrated in Figure 5, the weight of the CS matrix tablets (CS45K and CS200K) was $2.6 \%$ to $5 \%$ greater than that of the CS salt matrix tablets after 6 months of storage. The weight change of matrix tablets containing CS was consistent with the tablet hardness results; CS can absorb moisture during storage, resulting in low physical hardness ${ }^{25}$. In addition, the weight of matrix tablets containing CS salts with/without drug increased after storage. The exception is the weight of theophylline-loaded matrix tablets containing CL, which decreased after storage. This finding can be attributed to the fact that lactic acid has a low boiling point $\left(122^{\circ} \mathrm{C}\right)$, resulting in the evaporation of lactic acid during the long storage period $^{26}$. 

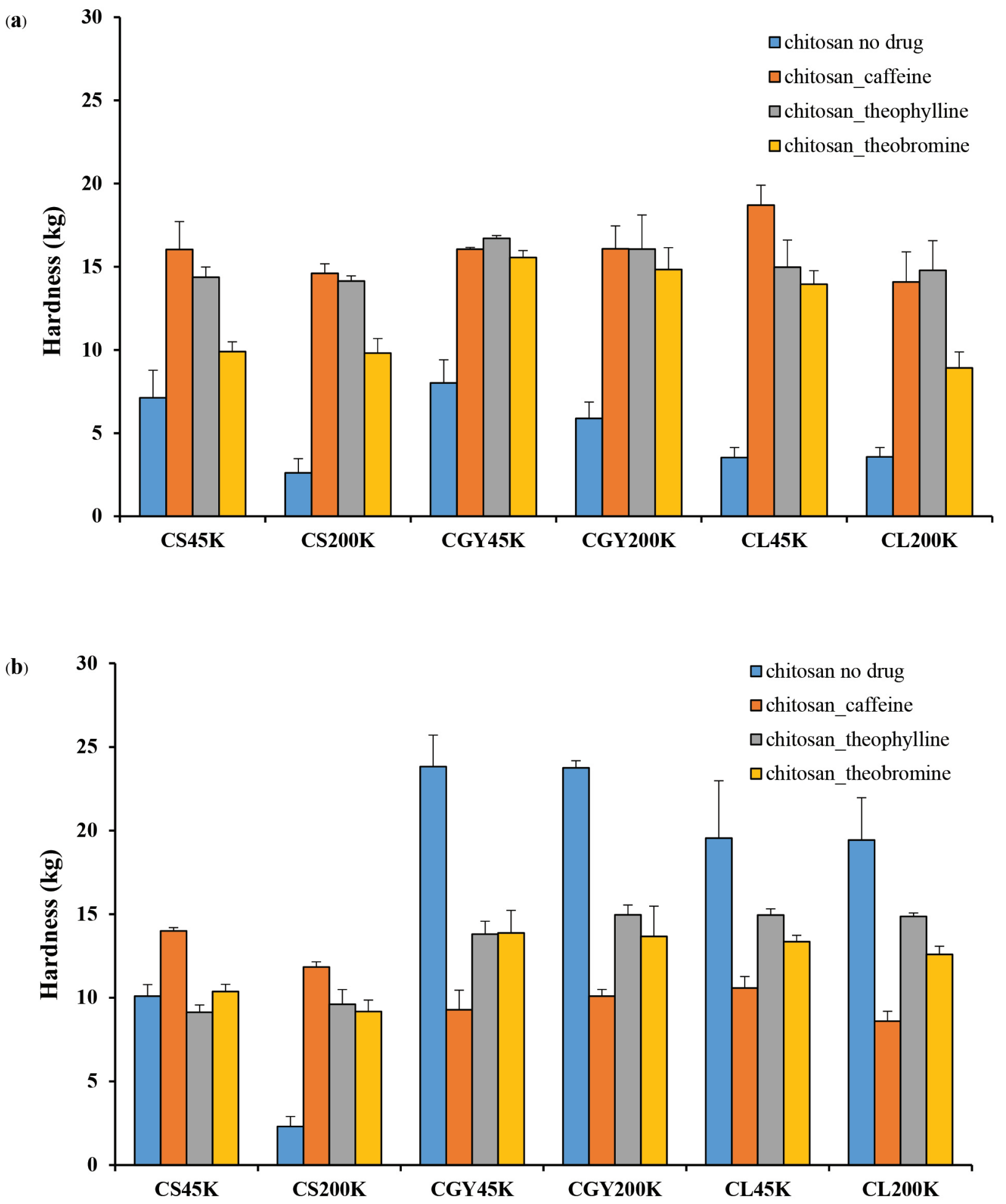

Figure 3. Tablet hardness of matrix tablets containing CS or CS salts (a) on the first day and (b) after 6 months of storage. 


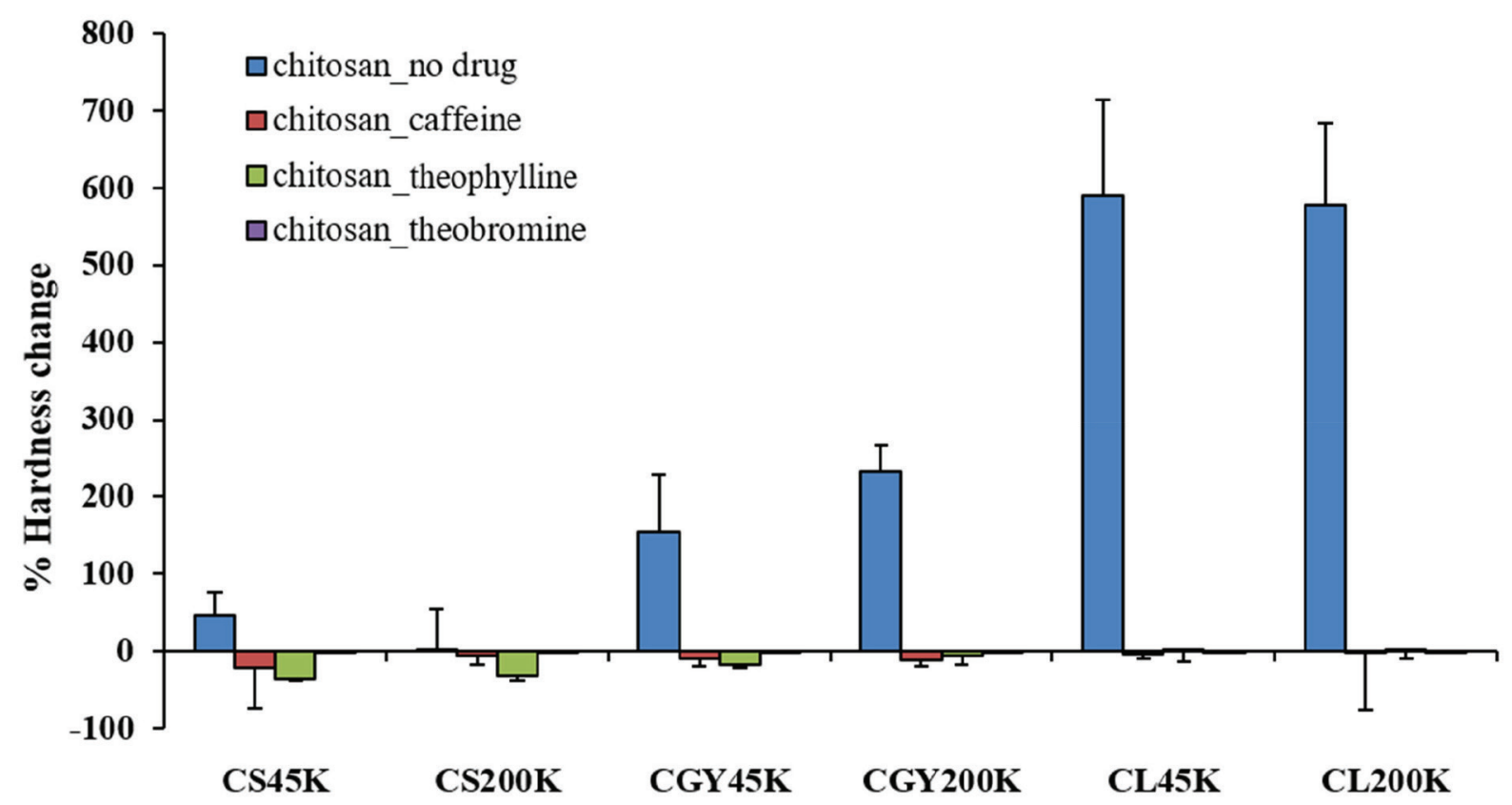

Figure 4. Percentage of tablet hardness change after 6 months of storage of matrix tablets made of CS or CS salts

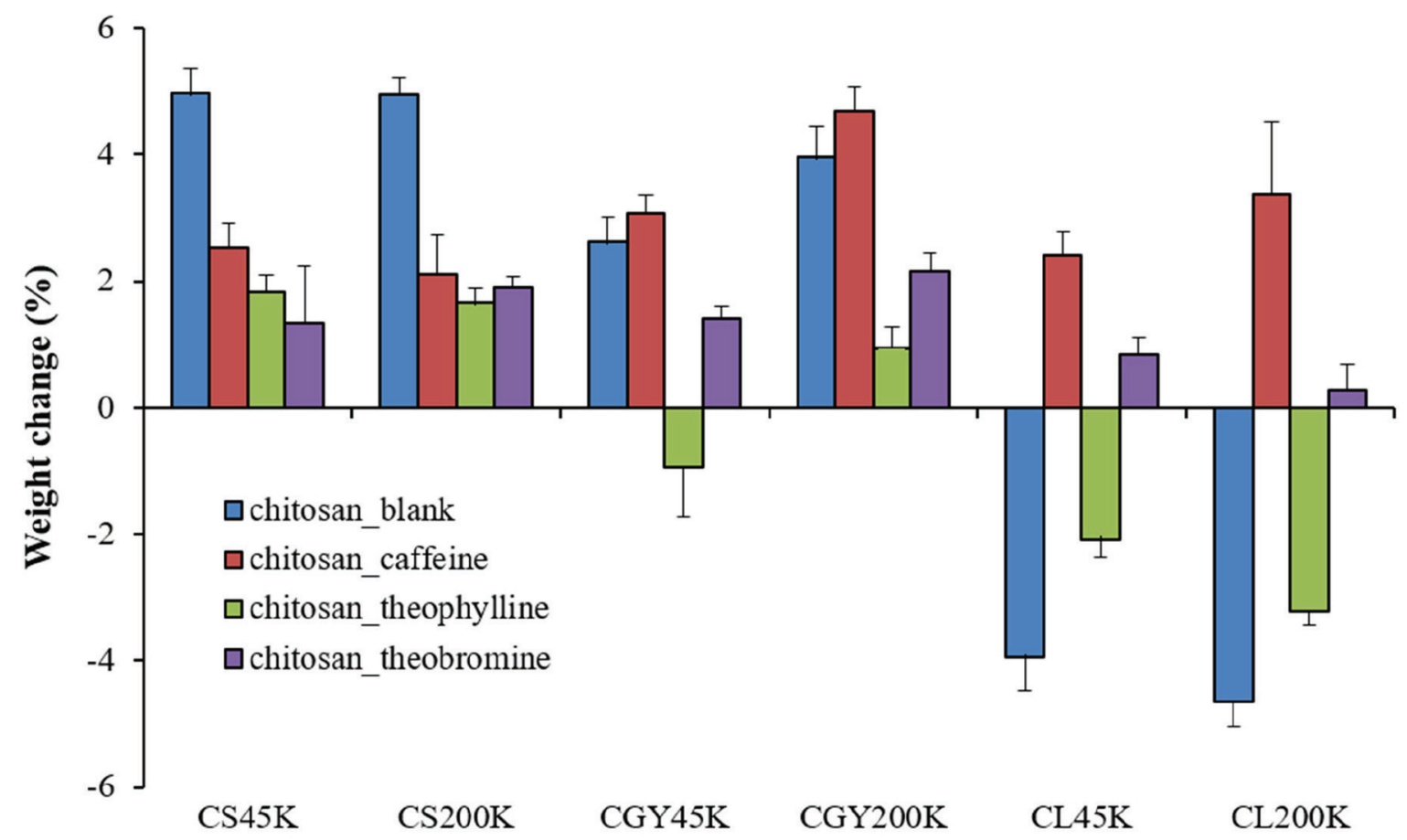

Figure 5. Percentage of weight change of blank and drug-loaded matrix tablets made of CS or CS salts after 6 months of storage 


\subsection{In vitro release studies}

Drug release from the matrix tablets made of CS, CGY, and CL (MW of 45 and $200 \mathrm{kDa}$ ) was tested. Three model drugs with similar structure (i.e., caffeine, theophylline, and theobromine) were selected in this study because of their difference in solubility. According to a previous study, the solubility of caffeine is higher than that of theophylline; meanwhile, theobromine has the lowest solubility ${ }^{27}$. Figure 6 shows the in vitro caffeine release from matrix tablets containing different CS salts. Notably, the release of caffeine from the tablets stored for 6 months was slower than that of freshly prepared tablets. CS in salt forms ( $\mathrm{CL}$ and $\mathrm{CGY}$ ) could extend drug release, compared with native CS. When loaded with theophylline (Figure 7), CS and its salts with high MW (i.e., $200 \mathrm{kDa}$ ) retarded drug release better than those with low MW (i.e., $45 \mathrm{kDa}$ ). After 6 months of storage, theophylline release from CS and CGY was fast. For the drug with the lowest solubility in this study, i.e., theobromine, drug release from the matrix tablets made of CS, both 45 and $200 \mathrm{kDa}$, on the first day and after 6 months of storage were not statistically different (Figure 8). The slowest theobromine release was observed when using $45 \mathrm{kDa} C L$ and $45 \mathrm{kDa}$ CGY. It can also be concluded that the type of CS salts and MW influenced the drug release behavior. The 6 months of storage of the matrix tablets altered the drug release behavior of the tablets made of CS and CS salts. This finding can be attributed to the fact that CL and CGY were not chemically stable under the accelerated storage condition. When the tablets were stored for 6 months, color change of the tablets containing CS salts was observed (data not shown) ${ }^{18}$. In addition, drug release from the tablets containing CS salts (CL and CGY) was slower than that from the tablets containing CS. This phenomenon can be attributed to the previously reported finding that the particles of CS salts could swell to larger sizes than the particles of $\mathrm{CS}^{2}$, which could lead to the slow penetration of the water molecules into the tablets.
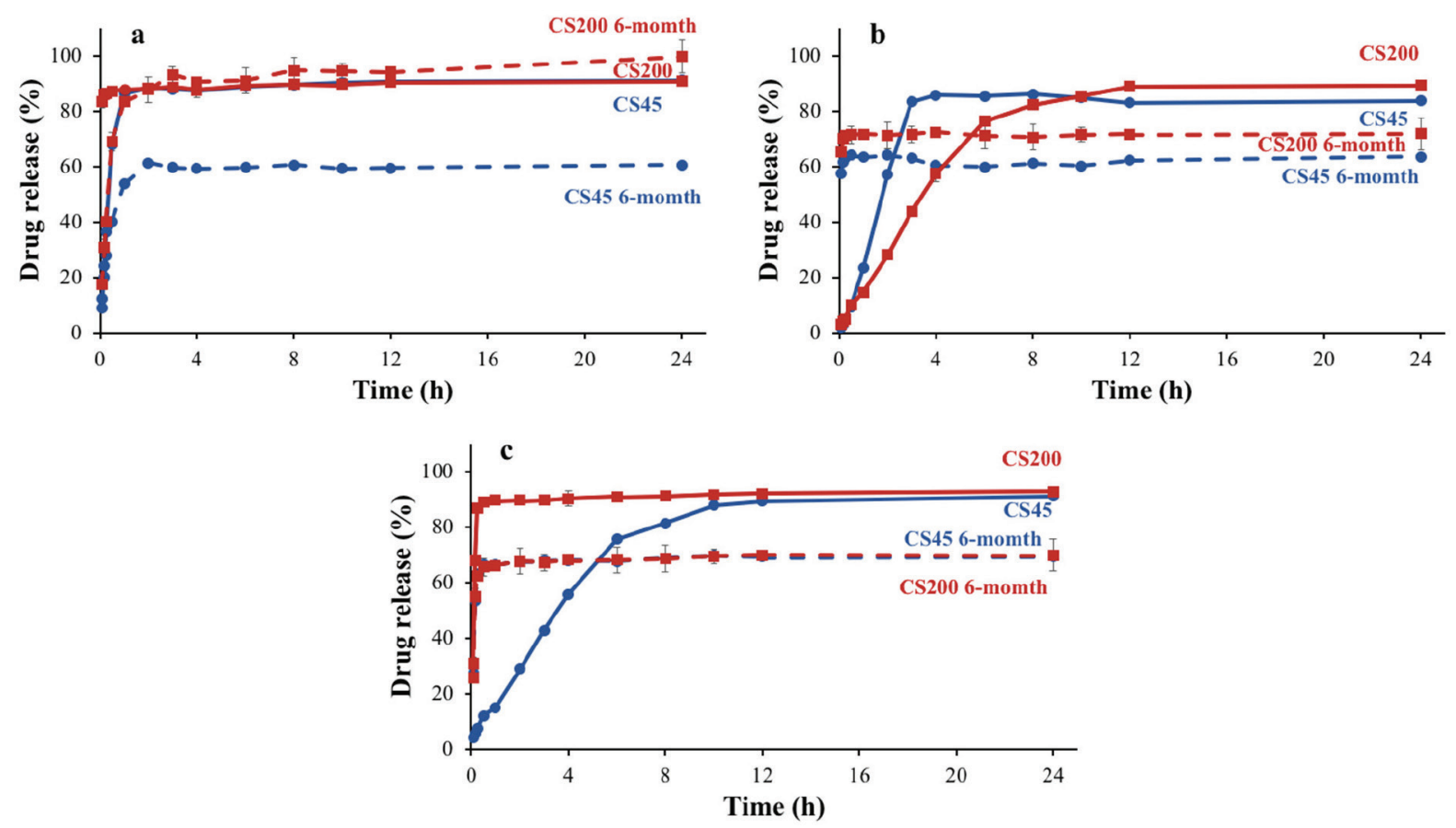

Figure 6. In vitro caffeine release from matrix tablets containing (a) CS, (b) CL, and (c) CGY 

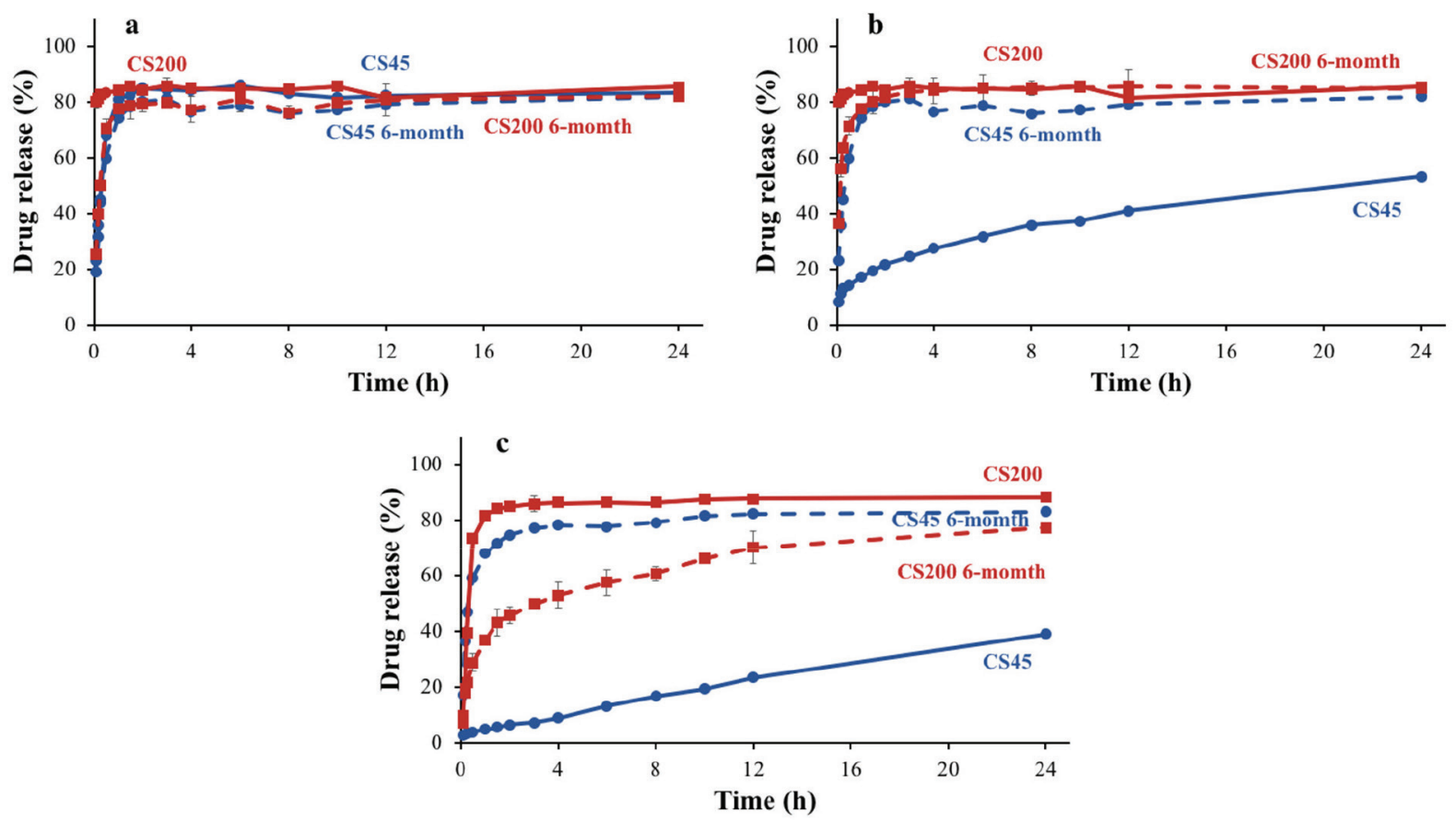

Figure 7. In vitro theophylline release from matrix tablets containing (a) CS, (b) CL, and (c) CGY
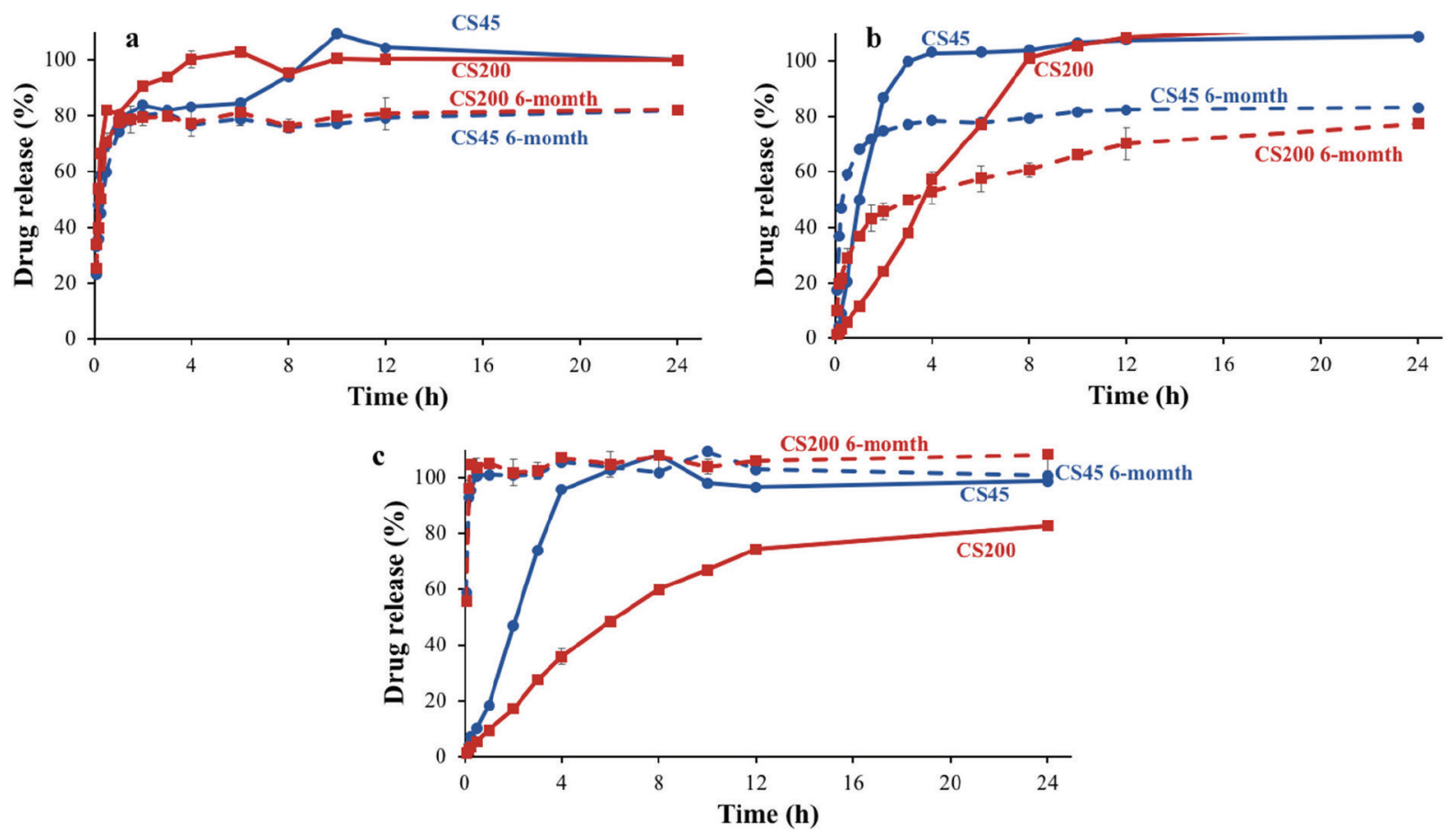

Figure 8. In vitro theobromine release from matrix tablets containing (a) CS, (b) CL, and (c) CGY 


\section{CONCLUSION}

The physical properties of the blank and drug-loaded matrix tablets containing CS or its salts were altered after 6 months of storage. The blank matrix tablets made of CS and CS salts were likely to be harder than the drug-loaded matrix tablets made of CS and CS salts, and the weight of most tablets increased. In vitro drug release was also affected by aging of the polymer. The drug tends to be released slower from the matrix tablets made of CS salts than from the matrix tablets made of CS after storage for 6 months. This finding can be attributed to the hygroscopic nature of CS, which means that it has a high capability to form the hydrogen bond with water. Thus, when using a high proportion of CS, either base or salt form, as a tablet excipient, its physical stability that could influence the drug release behavior should be considered

\section{Conflict of interest (If any)}

The authors declare no conflicts of interest arising in this research.

\section{Funding}

None to declare

\section{Ethical approval}

None to declare

\section{Article info:}

Received September 24, 2019

Received in revised form February 10, 2020

Accepted February 12, 2020

\section{REFERENCES}

1. Nunthanid J, Puttipipatkhachorn S, Yamamoto K, Peck GE. Physical properties and molecular behavior of chitosan films. Drug Dev. Ind. Pharm. 2001;27(2):143-57.

2. Huanbutta K, Sriamornsak P, Limmatvapirat S, Luangtana-anan M, Yoshihashi Y, Yonemochi E, et al. Swelling kinetics of spray-dried chitosan acetate assessed by magnetic resonance imaging and their relation to drug release kinetics of chitosan matrix tablets. Eur. J. Pharm. Biopharm. 2011;77(2):320-6.

3. Nunthanid J, Huanbutta K, Luangtana-anan M, Sriamornsak P, Limmatvapirat S, Puttipipatkhachorn S. Development of time-, $\mathrm{pH}$-, and enzyme-controlled colonic drug delivery using spray-dried chitosan acetate and hydroxypropyl methylcellulose. Eur. J. Pharm. Biopharm. 2008; 68(2):253-9.

4. Huanbutta K, Sriamornsak P, Luangtana-Anan M, Limmatvapirat S, Puttipipatkhachorn S, Lim L-Y, et al. Application of multiple stepwise spinning disk processing for the synthesis of poly (methyl acrylates) coated chitosan-diclofenac sodium nanoparticles for colonic drug delivery. Eur. J. Pharm. Sci. 2013;50(3-4):303-11.

5. Huanbutta K, Luangtana-Anan M, Sriamornsak P, Limmatvapirat S, Puttipipatkhachorn S, Nunthanid J. Factors affecting preparations of chitosan microcapsules for colonic drug delivery. J. Met. Mat. Miner. 2008;18(2):79-83.

6. Orienti I, Cerchiara T, Luppi B, Bigucci F, Zuccari G, Zecchi V. Influence of different chitosan salts on the release of sodium diclofenac in colon-specific delivery. Int. J. Pharm. 2002; 238(1-2):51-9

7. Huanbutta K, Terada K, Sriamornsak P, Nunthanid J. Simultaneous X-ray diffractiondifferential scanning calorimetry and physicochemical characterizations of spray dried drugs and chitosan microspheres. Walailak J. Sci. Tech. 2015;13(10):849-61.

8. Maestrelli F, Zerrouk N, Chemtob C, Mura P. Influence of chitosan and its glutamate and hydrochloride salts on naproxen dissolution rate and permeation across Caco-2 cells. Int. J. Pharm. 2004;271(1-2):257-67.

9. Nunthanid J, Laungtana-Anan M, Sriamornsak P, Limmatvapirat S, Puttipipatkhachorn S, Lim LY, et al. Characterization of chitosan acetate as a binder for sustained release tablets. J. Control. Release. 2004;99(1):15-26.

10. Bani-Jaber A, Kobayashi A, Yamada K, Haj-Ali D, Uchimoto T, Iwao Y, et al. A newly developed lubricant, chitosan laurate, in the manufacture of acetaminophen tablets. Int. J. Pharm. 2015; 483(1-2):49-56.

11. Drechsler M, Garbacz G, Thomann R, Schubert R. Development and evaluation of chitosan and chitosan/Kollicoat ${ }^{\circledR}$ Smartseal 30 D film-coated tablets for colon targeting. Eur. J. Pharm. Biopharm. 2014;88(3):807-15.

12. Anraku M, Hiraga A, Iohara D, Pipkin JD, Uekama K, Hirayama F. Slow-release of 
famotidine from tablets consisting of chitosan/ sulfobutyl ether $\beta$-cyclodextrin composites. Int. J. Pharm. 2015;487(1-2):142-7.

13. He P, Davis SS, Illum L. Chitosan microspheres prepared by spray drying. Int. J. Pharm. 1999; 187(1):53-65.

14. Qinna NA, Akayleh FT, Al Remawi MM, Kamona BS, Taha H, Badwan AA. Evaluation of a functional food preparation based on chitosan as a meal replacement diet. J. Funct. Foods. 2013;5(3):1125-34.

15. Nunthanid J, Luangtana-Anan $M$, Sriamornsak $P$, Limmatvapirat S, Huanbutta K, Puttipipatkhachorn S. Use of spray-dried chitosan acetate and ethylcellulose as compression coats for colonic drug delivery: Effect of swelling on triggering in vitro drug release. Eur. J. Pharm. Biopharm. 2009;71(2):356-61.

16. Luangtana-anan M, Nunthanid J, Limmatvapirat S. Potential of different salt forming agents on the formation of chitosan nanoparticles as carriers for protein drug delivery systems. J. Pharm. Investig. 2019;49(1):37-44.

17. Sriamornsak P, Kennedy RA. A novel gel formation method, microstructure and mechanical properties of calcium polysaccharide gel films. Int. J. Pharm. 2006;323(1-2):72-80.

18. Huanbutta K, Cheewatanakornkool K, Terada K, Nunthanid J, Sriamornsak P. Impact of salt form and molecular weight of chitosan on swelling and drug release from chitosan matrix tablets. Carbohydr. Polym. 2013;97(1):26-33.

19. Kitazawa S, Johno I, Ito Y, Teramura S, Okada J.
Effects of hardness on the disintegration time and the dissolution rate of uncoated caffeine tablets. J. Pharm. Pharmacol. 1975;27(10):765-70.

20. Gaudy D, Joachim J, Duru C, Puech A, Jacob M. Dosage forms and bioavailability of theophylline. III. The influence of the hardness factor. Pharm. Acta Helv. 1987;62(2):37-41.

21. Sahasathian T, Kerdcholpetch T, Chanweroch A, Praphairaksit N, Suwonjandee N, Muangsin N. Sustained release of amoxicillin from chitosan tablets. Arch. Pharm. Res. 2007;30(4):526-31.

22. Garr J, Rubinstein M. The influence of moisture content on the consolidation and compaction properties of paracetamol. Int. J. Pharm. 1992; 81(2-3):187-92.

23. Szymańska E, Winnicka K. Stability of chitosana challenge for pharmaceutical and biomedical applications. Mar. Drugs. 2015;13(4):1819-46.

24. Rinaudo M. Chitin and chitosan: Properties and applications. Prog. Polym. Sci. 2006;31(7): 603-32.

25. No HK, Prinyawiwatkul W. Stability of chitosan powder during long-term storage at room temperature.J.Agric.FoodChem.2009;57(18): 8434-8.

26. Brotz P, Schaefer D. Simultaneous determination of lactic and volatile fatty acids in microbial fermentation extract by gas-liquid chromatography. J. Microbiol. 1987;6(3):139-44.

27. Sriamornsak P, Kennedy RA. Effect of drug solubility on release behavior of calcium polysaccharide gel-coated pellets. Eur. J. Pharm. Sci. 2007;32(3):231-9. 